\title{
Studies of the Pro12Ala polymorphism of the peroxisome proliferator-activated receptor- $\gamma 2$ (PPAR- $\gamma 2$ ) gene in relation to insulin sensitivity among glucose tolerant Caucasians
}

\author{
J. Ek ${ }^{1}$, G. Andersen ${ }^{1}$, S. A. Urhammer ${ }^{1}$, L.Hansen ${ }^{1}$, B. Carstensen ${ }^{1}$, K. Borch-Johnsen ${ }^{1}$, T. Drivsholm ${ }^{2}$, L. Berglund ${ }^{3}$, \\ T. Hansen ${ }^{1}$, H. Lithell ${ }^{3}$, O. Pedersen ${ }^{1}$ \\ ${ }^{1}$ Steno Diabetes Center and Hagedorn Research Institute, Copenhagen, Denmark \\ ${ }^{2}$ Centre of Preventive Medicine, Glostrup University Hospital, Denmark \\ ${ }^{3}$ Department of Geriatrics, Uppsala University, Sweden
}

\section{Abstract}

Aims/hypothesis. We examined whether the Pro12Ala polymorphism of the human peroxisome proliferator-activated receptor- $\gamma 2(P P A R-\gamma 2)$ gene was related to altered insulin sensitivity among glucose-tolerant subjects or a lower accumulated incidence or prevalence of IGT and Type II (non-insulin-dependent) diabetes mellitus among Scandinavian Caucasians.

Methods. The Pro12Ala polymorphism was examined using PCR-RFLP. Whole-body insulin sensitivity measured under hyperinsulinaemic-euglycaemic conditions was estimated in a population-based sample of 616 glucose tolerant Swedish Caucasian men at age 70 . In addition, insulin sensitivity index was measured using IVGTT and Bergman minimal modelling in a population-based sample of 364 young healthy Danish Caucasians. Finally, we evaluated whether the polymorphism predicted Type II diabetes and IGT in 841 seventy-year-old Swedish men. A case-control study was carried out in 654 unrelated
Danish Type II diabetic patients and 742 Danish glucose tolerant subjects matched for age and sex.

Results. Whole-body insulin sensitivity was significantly improved in carriers compared with non-carriers of the Ala-allele of the codon 12 polymorphism in Swedish Caucasian men $(6.0 \pm 2.5$ vs $5.6 \pm 2.5 \mathrm{mg}$. $\left.\mathrm{kg}^{-1} \cdot \mathrm{min}^{-1} \cdot[\mathrm{mU} / 1]^{-1} \cdot 100, p=0.044\right)$. The same tendency, but not significant, was observed in the insulin sensitivity index among the group of young healthy Danish Caucasians. The incidence of Type II diabetes and IGT among the Swedish subjects at the age of 70 was similar in the three genotype-groups of the Pro12Ala variant and the Ala-allele was not related to a lower prevalence of Type II diabetes in Danish Caucasians.

Conclusion/interpretation. The Ala-allele of the PPAR $-\gamma 2$ polymorphism is associated with improved whole body insulin sensitivity among Swedish Caucasians. [Diabetologia (2001) 44: 1170-1176]

Keywords PPAR- $\gamma 2$, polymorphism, insulin sensitivity, Type II diabetes, obesity, epidemiology, genetics.
Type II (non-insulin-dependent) diabetes mellitus is phenotypically and genetically a heterogeneous disorder resulting from defects in insulin secretion and insulin action [1]. Mutations in several genes linked to monogenic forms of Type II diabetes have been

Received: 27 March 2001 and in revised form: 5 June 2001

Corresponding author: J.Ek, Steno Diabetes Center and Hagedorn Research Institute, Niels Steensens Vej 2, 2820 Gentofte, Copenhagen, Denmark

Abbreviations: PPAR- $\gamma$, peroxisome proliferation-activated receptor- $\gamma$; OHA, oral hypoglycaemic agents identified [2-7] and recently, a common $\mathrm{G} \rightarrow \mathrm{A}$ transition within intron 3 of the CAPN10 gene (UCSNP43 ) in combination with specific polymorphisms in other locations within $C A P N 10$ was associated with Type II diabetes [8]. However, in the vast majority of Type II diabetic patients the genetic mechanism and the pathogenesis behind the disease are still not clear.

The peroxisome proliferator-activated receptor- $\gamma$ $(\operatorname{PPAR}-\gamma)$ is a transcription factor, involved in adipogenesis and in the regulation of adipocyte gene expression [9]. PPAR $\gamma$ exists in three different isoforms [10]. Two mutations in the ligand-binding domain of PPAR- $\gamma$, Pro467Leu and Val290Met, were found in 
three Caucasian subjects with severe insulin resistance and Type II diabetes. Of interest, these subjects had normal body weight [11]. Within a unique domain of PPAR- $\gamma 2$ that enhances ligand-independent activation [12] a prevalent Pro12Ala polymorphism has been identified [13]. The polymorphism was shown to be involved in the pathogenesis of obesity [14-16] and a study using a family based design to control for population stratification, reported that the Ala-allele of the codon 12 polymorphism was associated with decreased risk of Type II diabetes [17]. The mechanism of these effects of the Ala-allele in PPAR- $\gamma 2$ is not fully understood.

We therefore examined whether the Ala-allele of the codon 12 polymorphism of the PPAR- $\gamma 2$ gene was related to an altered insulin sensitivity of glucose tolerant subjects or whether the Ala-allele predicted a decreased risk of Type II diabetes in 70-year-old men or was associated with a lower prevalence of Type II diabetes in Scandinavian Caucasians.

\section{Subjects and methods}

Subjects. In total, 841 men from the Uppsala Health Survey Study participated in our study. Briefly, from 1970 to 1973 , all 50-year-old Swedish Caucasian men $(n=2.841)$ who were born between 1920 and 1924, living in the municipality of Uppsala were invited to participate in a health survey study that originally included an intravenous glucose tolerance test (IVGTT). Those with normal fasting plasma glucose concentrations (plasma glucose $<6.7 \mathrm{mmol} / \mathrm{l}$ ) and a normal intravenous glucose tolerance test (glucose disappearance rate-constant, $\mathrm{K}>0.9)$ at age 50 years $(n=1680$, baseline) [18] were invited for a re-examination in 1992 to 1994 (20-year status, at age 70 years), which included an OGTT and a hyperinsulinaemiceuglycaemic clamp [19]. The participation rate was $73 \%$ $(n=1.226)$ and of the participants from whom DNA was available $(n=841), 616$ were glucose tolerant and 225 had diabetes or impaired glucose tolerance (IGT) at re-examination [19]. The Ethics Committee of the Faculty of Medicine at the University of Uppsala approved the study. Further, the insulin sensitivity index was investigated in a population-based sample of 364 young healthy Danish Caucasians aged 18 to 32 years who underwent an IVGTT. The physiological characteristics of this population sample have been presented previously [20].

We did an association study on 654 unrelated Type II diabetic patients recruited from the outpatient clinic at the Steno Diabetes Center and 742 glucose tolerant control subjects matched for age and sex sampled from the same area of Copenhagen. Of the 742 control subjects, 335 were unrelated and glucose tolerant subjects sampled randomly from the Danish Central Population Register and 407 subjects were available from a population based study of 695 glucose tolerant Caucasian subjects born in 1936 who were examined in random order between May 7, 1996 and September 16, 1997, at the Copenhagen County Centre of Preventive Medicine. All investigated variables and measured standard deviations were completely comparable. The Type II diabetic patients had a mean age of clinical diabetes onset of 55 years. More than $80 \%$ of the patients fulfilled the criteria for the metabolic syndrome according to the 1999 WHO-criteria [21], $28 \%$ of the patients were treated with diet alone, $60 \%$ with oral hypo- glycaemic agents (OHA), and $12 \%$ with insulin alone or in combination with OHA. Informed written consent was obtained from all subjects prior to participation and was carried out in accordance with the principles of the Helsinki Declaration II. All participants from the Danish studies were Danish Caucasians by self-identification and the ethics committee of Copenhagen approved these studies.

Measurement of clinical and biochemical variables. At age 50 years, the cohort of 841 Swedish men all underwent an IVGTT with measurements of serum insulin and plasma glucose. Subjects with treated diabetes or with fasting plasma glucose of $6.7 \mathrm{mmol} / \mathrm{l}$ or more or a disappearance rate-constant of glucose (K-value) above 0.9 during the IVGTT were excluded [18]. At age 70 whole-body insulin sensitivity was measured using a 120-min hyperinsulinaemic-euglycaemic clamp (56 mU . $\min ^{-1} \cdot \mathrm{m}^{-2}$ ) with a mean steady state of approximately $100 \mathrm{mU} / \mathrm{l}$ of serum insulin concentration [19]. Each of the 364 young healthy Danish Caucasians underwent an IVGTT after a 12-h overnight fast, i.e. an intravenous injection of $0.3 \mathrm{~g}$ glucose per kg body weight at time zero in combination with intravenous injection of $3 \mathrm{mg}$ tolbutamide per $\mathrm{kg}$ body weight after $20 \mathrm{~min}$ [22]. The insulin sensitivity index was calculated using the Bergman MINIMOD computer programme developed specifically for the combined intravenous glucose and tolbutamide tolerance test [23]. Waist-circumference was measured midway between the lower rib and the iliac crest. Hip-circumference was measured at the point yielding the maximum circumference over the buttocks. Both variables were measured when participants were standing and to the nearest $0.5 \mathrm{~cm}$. The plasma concentration of glucose in Danish subjects was measured by an automated glucose oxidase method (Granutest: Merck, Darmstadt, Germany) whereas plasma glucose in Swedish subjects was measured by a glucose dehydrogenase method. In Danish subjects the concentration of insulin (excluding des(31, 32)- and intact proinsulin) in serum was measured by ELISA using Steno Diabetes Center routine methods and in Swedish subjects it was analysed using an enzymatic-immunological assay.

Screening for the Pro12Ala polymorphism in PPAR- $\gamma 2$. The screening for the Pro12Ala polymorphism was carried out on genomic DNA isolated from human leucocytes and using PCR and subsequent restriction enzyme analysis with HpaII [14].

Statistical methods. Significant differences in allelic frequencies between diabetic and non-diabetic subjects were examined by Fisher's exact test. Differences in continuous variables between genotypes were tested with Student's $t$ test. Before analysis, the residuals were checked for normality. Values of insulin were logarithmically transformed. The tested phenotypic variables were adjusted for age, sex and BMI. Trend test and Spearman correlations analysis were used to test for gene dosage effects. We did a meta-analysis using published data on the frequency of the Pro12Ala polymorphism. In studies where genotype information was available (eight studies) we tested whether the genotype distribution was in Hardy-Weinberg equilibrium, and if the allele effect was additive. The effect of the Ala-allele was analysed on the basis of alleles, i.e. each allele gives rise to one binary observation (case or control), classified by study and allele. Analysis was done as a logistic regression with effect of size of the study and number of Ala-alleles among subjects investigated. This is equivalent to a Mantel-Haenszel analysis. It was assumed that the Ala-allele had different effects among Caucasians and Asians, and tested whether the studies among Europeans and among Asians were 
Table 1. Clinical and biochemical characteristics of 616 glucose tolerant seventy-year-old Swedish Caucasian men classified according to PPAR- $\gamma 2$ Pro12Ala genotype

\begin{tabular}{lllll}
\hline & Pro/Pro & Pro/Ala & Ala/Ala & $p$ \\
\hline$n$ & 456 & 148 & 12 & - \\
BMI $\left(\mathrm{kg} / \mathrm{m}^{2}\right)$ & $25.6 \pm 3.0$ & $25.7 \pm 3.1$ & $25.2 \pm 4.9$ & - \\
Waist-to-hip ratio & $0.94 \pm 0.05$ & $0.94 \pm 0.06$ & $0.97 \pm 0.07$ & $0.14(0.024)$ \\
Fasting $p$-glucose $(\mathrm{mmol} / \mathrm{l})$ & $5.3 \pm 0.5$ & $5.3 \pm 0.6$ & $12 \pm 6$ & 0.2 \\
Fasting $s$-insulin $(\mathrm{mU} / \mathrm{l})$ & $12 \pm 7$ & $5.9 \pm 2.5$ & $6.5 \pm 2.2$ \\
Insulin sensitivity $\left(\mathrm{mg} \cdot \mathrm{kg}^{-1} \cdot \mathrm{min}^{-1} \cdot[\mathrm{mU} / 1]^{-1} \cdot 100\right)$ & $5.6 \pm 2.5$ & $0.93)$ \\
\hline
\end{tabular}

Data are means \pm SD. Insulin sensitivity was measured from 60 to 120 min during a 2-h, hyperinsulinaemic clamp. $p$ values were adjusted for BMI and compares subjects with or without

the Ala-allele calculated by an unpaired Student's $t$ test. $p$ values (in parentheses) were obtained with trend test and Spearman correlation test after correction for BMI

Table 2. Clinical and biochemical characteristics of 364 young healthy Danish Caucasian subjects classified according to PPAR- $\gamma 2$ Pro12Ala genotype

\begin{tabular}{lccc}
\hline & Pro/Pro & Pro/Ala + & Ala/Ala \\
\hline$n$ (men/ women) & $270(127 / 143)$ & $81(52 / 29)$ & $13(5 / 8)$ \\
Age (years) & $25.2 \pm 3.8$ & $24.7 \pm 3.6$ & $26.9 \pm 3.5$ \\
BMI $\left(\mathrm{kg} / \mathrm{m}^{2}\right)$ & $23.5 \pm 3.6$ & $23.0 \pm 3.0$ & $23.8 \pm 4.2$ \\
Waist-to-hip ratio & $0.81 \pm 0.07$ & $0.83 \pm 0.06$ & $0.82 \pm 0.06$ \\
Fasting $p$-glucose $(\mathrm{mmol} / \mathrm{l})$ & $5.0 \pm 0.5$ & $5.0 \pm 0.4$ & $4.9 \pm 0.4$ \\
Fasting $s$-insulin $(\mathrm{pmol} / \mathrm{l})$ & $38 \pm 22$ & $36 \pm 25$ & $33 \pm 16$ \\
Insulin sensitivity index $\left(10^{-5}(\mathrm{~min} \cdot \mathrm{pmol} / \mathrm{l})^{-1}\right)$ & $14.9 \pm 8.6$ & $15.8 \pm 9.8$ & 0.21 \\
\end{tabular}

Data are means \pm SD. Insulin sensitivity index was measured applying Bergman's minimal model computing of data obtained during an intravenous glucose and tolbutamide tolerance test. $p$ values were adjusted for sex, age, and BMI and compares subjects with or without the Ala-allele calculated by an unpaired Student's $t$ test. $p$ values (in parentheses) were obtained with trend test and Spearman correlation test after correction for sex, age, and BMI homogeneous in relation to effect of the Ala-allele. Estimates from the logistic regression are given as odds-ratios with $95 \%$ confidence intervals. Tests were carried out as likelihood-ratio tests. All tests were two-sided and a $p$ value of less than 0.05 was considered statistically significant.

\section{Results}

In the cohort of 616 normal glucose tolerant Swedish Caucasian men, a significantly higher whole-body insulin sensitivity index measured by a hyperinsulinaemic-euglycaemic clamp was found among those with at least one Ala-allele when compared to those subjects without $\left(5.6 \pm 2.5\right.$ vs $6.0 \pm 2.5 \mathrm{mg} \cdot \mathrm{kg}^{-1}$. $\left.\min ^{-1} \cdot[\mathrm{mU} / 1]^{-1} \cdot 100, p=0.044\right)$ (Table 1). In the same cohort a significant trend was found towards an improved insulin sensitivity index with increasing gene dosage of the Ala-allele $(p=0.041)$ and with lowered fasting plasma glucose $(p=0.024)$ (Table 1$)$. No differences were found in BMI or waist-to-hip ratio, between carriers and non-carriers of the Ala-allele (Table 1). In the 364 young healthy Danish Caucasians, the insulin sensitivity index using IVGTT and Bergman minimal modelling, BMI, and waistto-hip ratio did not differ significantly between wild type, heterozygous and homozygous carriers of the Pro12Ala polymorphism in the PPAR- $\gamma 2$ gene (Table 2). However, there was a non-significant tendency towards an increased insulin sensitivity index with increased gene dosage of the Ala-allele $(14.9 \pm 8.6$ vs $15.8 \pm 9.8$ vs $19.9 \pm 16.110^{-5}(\mathrm{~min} \cdot \mathrm{pmol} / \mathrm{l})^{-1}$, trend test: $p=0.16$, Pro12Pro vs Pro12Ala + Ala12Ala: $p=0.37)$ (Table 2).

To predict Type II diabetes and IGT, the three genotype groups of the Pro12Ala polymorphism, Pro12Pro, Pro12Ala, and Ala12Ala were investigated within the group of 841 Swedish men at the age of 70. The distribution of the three genotypes was similar in groups of Type II diabetic patients and subjects with IGT and in normal glucose tolerant subjects $(p=0.47)$ (Table 3).

The allelic frequency of the Ala-allele of the codon 12 polymorphism was $12.0 \% \quad(95 \%$ CI: 9.5-14.5\% ) among 654 Type II diabetic patients compared to $14.0 \%$ (11.5-16.5\% ) among 742 glucose tolerant control subjects $(p=0.22)$ (Table 4). All genotype frequencies were in Hardy-Weinberg equilibrium.

We did a meta-analysis on all published data on the Pro12Ala variant. Analysis of eight studies with available genotype information revealed that all were in Hardy-Weinberg equilibrium and that there were additive effects of the allele. Hence, we analysed the data on the basis of alleles, also including two studies [27, 32] where the basic assumptions were not testable (Table 5). All studies showed an estimated odds ratio for the Ala-allele of 0.81 (95\% CI: 
Table 3. Prevalence of Type II diabetes in 841 Swedish Caucasians classified according to genotype of PPAR- $\gamma 2$

\begin{tabular}{|c|c|c|c|c|c|}
\hline \multirow[t]{2}{*}{$\begin{array}{l}\text { Swedish subjects aged } 70 \text { after } \\
20 \text { years of follow-up }\end{array}$} & \multirow[b]{2}{*}{ Total } & \multicolumn{4}{|c|}{$\begin{array}{l}\text { Distribution of genotypes among patients with Type II diabetes } \\
\text { and IGT compared with normal glucose tolerant subjects (\%) }\end{array}$} \\
\hline & & Pro/Pro & Pro/Ala & Ala/Ala & $p$ \\
\hline Subjects with Type II diabetes or IGT & 225 & $174(77)$ & $49(22)$ & $2(1)$ & \\
\hline Glucose tolerant subjects & 616 & $456(74)$ & $148(24)$ & $12(2)$ & 0.47 \\
\hline
\end{tabular}

The $p$ value compares the distribution of the three genotypes of PPAR- $\gamma 2$ in the Type II diabetes group and the IGT group with normal glucose tolerant subjects

Table 4. PPAR- $\gamma 2$ genotype frequencies among Danish Caucasian subjects

\begin{tabular}{llllllrr}
\hline Danish Caucasians & $n$ & Pro/Pro & Pro/Ala & Ala/Ala & Ala frequency (\%) & $95 \%$ CI & $p$ \\
\hline Type II diabetic patients & 654 & 512 & 127 & 15 & 12.0 & $9.5 \%-14.5 \%$ \\
Glucose tolerant subjects & 742 & 552 & 172 & 18 & 14.0 & 0.22 \\
\hline
\end{tabular}

The $p$ value compares the allelic frequency of the codon 12 polymorphism of PPAR- $\gamma 2$ in the Type II diabetes group and the allelic frequency in the control group

$0.72-0.91, p=0.00034)$. The estimated odds-ratios associated with the Ala-allele was found to be different in Caucasian (odds ratio 0.85, 95\% CI: 0.76-0.96, $p=0.0040$ ) and Asian populations (odds ratio: 0.42, 95\% CI: $0.26-0.67, p=0.0067)$. The difference was highly significant $(p=0.0033)$ (Table 5). We did not observe any heterogeneity within the groups of Caucasian or Asian studies $(p=0.60)$.

\section{Discussion}

Our study shows a significantly improved insulin sensitivity index measured by a hyperinsulinaemic-euglycaemic clamp associated with the Ala-allele of the Pro12Ala polymorphism in PPAR- $\gamma 2$ in 616 normal glucose tolerant Swedish men. Carriers of the Ala-allele had on average a $7 \%$ increment in insulin sensitivity compared with non-carriers. Furthermore, analysis of all 841 subjects, which included Type II diabetic patients and patients with IGT revealed similar significant improvement of insulin sensitivity and also a trend for lowered fasting plasma glucose (data not shown).

Among 364 young healthy Danish Caucasians, the insulin sensitivity index applying Bergman's minimal model using IVGTT data showed a non-significant increase in insulin sensitivity index among carriers of the Ala-allele compared with non-carriers. Furthermore, a non-significantly increased insulin sensitivity was found with increased gene dosage of the Ala-allele. Thus, the same tendency towards an increased insulin sensitivity index was observed among Ala-carriers compared with non-carriers in these two study samples. However, among the young Danish subjects the increase did not reach statistical significance. We calculated the required sample size to detect a $7 \%$ increment in whole body insulin sensitivity among young Danish subjects carrying the Ala-allele. Given the standard deviation specified by Bergman's minimal model used for the sample of young Danish subjects and a power of $90 \%$, the required sample size is about 2000 subjects. This illustrates the need for large sample sizes in genotype/phenotype interaction studies to detect small effects of a gene variant and might explain why the observed increment in insulin sensitivity index among young Danish subjects failed to reach significance. In addition, the average age of the two groups varies considerably. The Danish subjects are young and a potential influence of the variant on the insulin sensitivity index might be more pronounced later in life.

In transfection studies, the Ala-allele of the Pro12Ala polymorphism showed decreased receptor activity compared with the Pro-allele [15]. In the same study, in 333 lean non-diabetic middle-aged Finnish subjects the Pro12Ala polymorphism was associated with lower BMI $(p=0.027)$ and improved insulin sensitivity $(p=0.047)$ as determined by an IVGTT applying Bergman's minimal model [15]. However, when the insulin sensitivity index was adjusted for BMI, the differences were no longer significant [15].

The Ala-allele of the polymorphism was also shown to be associated with an increased insulin sensitivity index in a subgroup of 19 obese subjects $\left(\mathrm{BMI}>30 \mathrm{~kg} / \mathrm{m}^{2}\right)$ chosen from 108 offspring from Type II diabetic patients [24]. When the whole group of offspring was analysed no significant association between the polymorphism and insulin sensitivity was found [24]. In an extended group of offspring from Type II diabetic patients in the same group of investigators showed a significantly improved insulin sensitivity index among carriers compared with noncarriers of the Ala-allele in two groups comprising 37 subjects, matched for sex, BMI, fat-distribution and body composition $(p=0.039)[25]$. 
Table 5. Allelic frequencies of the Ala-allele of the Pro12Ala variant of PPAR- $\gamma 2$ found in ten association studies of Type II diabetic patients and glucose tolerant control subjects

\begin{tabular}{|c|c|c|c|c|c|c|c|}
\hline \multirow[t]{2}{*}{ Subjects } & \multirow[t]{2}{*}{ Reference } & \multirow[b]{2}{*}{$\begin{array}{l}n \text { (Diabetic } \\
\text { patients/control } \\
\text { subjects) }\end{array}$} & \multicolumn{5}{|c|}{ Allelic frequencies } \\
\hline & & & $\begin{array}{l}\text { Diabetic } \\
\text { patients }\end{array}$ & $\begin{array}{l}\text { Control } \\
\text { subjects }\end{array}$ & Odds-ratio & $95 \% \mathrm{CI}$ & $p$ \\
\hline German Caucasians & [28] & $503 / 310$ & 0.14 & 0.15 & 0.97 & $0.72-1.29$ & 0.89 \\
\hline Italian Caucasians & [27] & $131 / 312$ & 0.13 & 0.18 & 0.67 & $0.44-1.01$ & 0.30 \\
\hline French Caucasians & {$[30]$} & $170 / 839$ & 0.10 & 0.11 & 0.87 & $0.59-1.28$ & 0.51 \\
\hline Scandinavian Caucasians & {$[17]$} & $481 / 481$ & 0.146 & 0.168 & 0.85 & $0.66-1.09$ & 0.071 \\
\hline French Canadian Caucasians & {$[17]$} & $127 / 127$ & 0.094 & 0.135 & 0.68 & $0.39-1.18$ & 0.080 \\
\hline Danish Caucasians & $\begin{array}{l}\text { Present } \\
\text { study }\end{array}$ & $654 / 742$ & 0.12 & 0.14 & 0.84 & $0.67-1.04$ & 0.22 \\
\hline Korean subjects & {$[31]$} & $58 / 111$ & 0.043 & 0.045 & 0.96 & $0.32-2.86$ & 1.00 \\
\hline $\begin{array}{l}\text { Meta-analysis based on studies } \\
\text { of Caucasians }\end{array}$ & & & & & $0.85^{*}$ & $0.76-0.96$ & 0.0040 \\
\hline $\begin{array}{l}\text { Meta-analysis based on studies } \\
\text { of Asians }\end{array}$ & & & & & $0.42 *$ & $0.26-0.67$ & 0.0067 \\
\hline
\end{tabular}

Fisher's exact test was applied to examine for significant differences in allele frequencies between diabetic and non-diabetic subjects. Analysis was done as a logistic regression with effect of size of the study and number of Ala-alleles among subjects investigated to examine for significant differences between diabetic and non-diabetic subjects among all published studies. Tests were carried out as likelihood-ratio tests $*(p=0.0033)$
Decreased insulin sensitivity plays a central part in the pathogenesis of Type II diabetes [26]. In our study, the prevalence of the Ala-allele of the codon 12 polymorphism in the $P P A R-\gamma 2$ gene did not differ significantly between 654 unrelated Type II diabetic patients and 742 glucose tolerant control subjects. The findings of a similar accumulated incidence of Type II diabetes in the three groups of different genotypes of the Pro12Ala polymorphism in the prospective study of 841 Swedish men are consistent with these data. The allelic frequencies are comparable with four previous studies of Caucasian subjects and one study of Korean subjects [27-31] which showed no association of the polymorphism with Type II diabetes. In contrast, an association to a lower frequency of the Ala-allele with Type II diabetes was reported in a cohort comprising 91 Type II diabetic (allelic frequency: $2.2 \%$ ) and 155 glucose tolerant (allelic frequency: $9.3 \%$ ) second-generation Japanese-Americans $(p=0.028)[15]$ and among 415 Type II diabetic Japanese patients (allelic frequency: 1.8\%) compared with 541 glucose tolerant control subjects (allelic frequency: $4.3 \%, p<0.05$ ) [32] (Table 5). However, among 215 non-diabetic Japanese men, living in Japan, the allelic frequency of the Ala-allele was $3 \%$ [33], which suggests an incidentally high frequency of the Ala-allele among the glucose tolerant control subjects in these studies $[15,33]$. Recently, using a family based association study approach it was shown that the Ala-allele of the codon 12 polymorphism was associated with a decreased risk of diabetes [17]. Subsequent analysis in 1.130 individuals from Scandinavian sibships discordant for Type II diabetes, 481 case-control pairs from Scandinavia, and 127 case-control pairs from Canada showed a modest but significant ( $p=0.045$ ) increase in diabetes risk associated with the more common Pro-allele. A metaanalysis of all published studies, revealed an estimated risk ratio for the Ala-allele of 0.79 [17]. Of interest, our data show a similar but non-significant odds ratio of 0.84 and the updated meta-analysis shows an estimated odds ratio for the Ala-allele of 0.81 . In addition, the present meta-analysis includes data from our study and a recently published association study of Korean Type II diabetic patients and normal glucose tolerant subjects [31].

Differences in the degree of obesity among the patients studied could partly explain the discrepancy of effect of the Pro12Ala polymorphism in single centre studies on diabetes risk and especially the divergent findings in Caucasian and Asian populations [15, 17, 27-32]. Asian populations tend to have lower BMI compared with Caucasians populations, probably partly because of environmental influences and lifestyle [33] but the differing prevalence of common mutations suggests that these differences could also be explained 
by variation in genetic background. Furthermore, a strong interaction has been found between the dietary fat intake and the Pro12Ala polymorphism for both BMI and fasting plasma insulin [34]. This gene-nutrient interaction could explain the heterogeneity of findings in different ethnic groups. Therefore, Asian studies might contribute heavily as an important single factor for the decreased risk of diabetes associated with the Ala-allele found in the meta-analysis of all published studies. In our analysis we found a significant $(p=0.0033)$ difference between Caucasian and Asian odds ratios, but still, a significantly decreased risk for developing diabetes in a meta-analysis comprising only Caucasian subjects $(p=0.0040)$.

The study of prediction of Type II diabetes and IGT in Swedish Caucasians seems to argue against the results of the meta-analysis of the prevalence of Type II diabetes. However, this discrepancy could be apparent because of the lack of statistical power. In our association study, the difference between allelic frequencies was two percent. To detect a two percent difference in allelic frequencies between diabetic patients and control subjects we calculated the number of participants necessary in one association study to be about 5000 subjects in each group, indicating the need for large population samples and/or meta-analysis in order to detect variants with a modest effect in the pathogenesis of Type II diabetes. In aggregate, we have shown a significant association of the Ala-allele of the Pro12Ala polymorphism with increased whole body insulin sensitivity in Swedish Caucasians. Therefore, it is likely that increased insulin sensitivity is one of the mechanisms by which the Ala-allele protects against Type II diabetes.

In conclusion, we found a modestly improved insulin sensitivity associated with the Ala-allele of the PPAR- $\gamma 2$ polymorphism. This might add to explain the minor protective effect of this allele against the risk of Type II diabetes seen in a meta-analysis of ten published case-control studies.

Acknowledgements. The study was supported by grants from the University of Copenhagen, the Velux Foundation, the Danish Diabetes Association, the Danish Medical Research Council, the Danish Heart Foundation, and EEC (BMH4CT-98-3084 and QLRT-CT-1999-00546). The authors thank A.Forman, L.Aabo, C.B.P. Søholm and B.Mottlau for their dedicated and careful technical assistance, C.Ekstrøm for statistical assistance, and G.Lademann for secretarial support.

\section{References}

1. Defronzo RA (1997) Pathogenesis of Type II diabetes metabolic and molecular implications for identifying diabetes genes. Diabetes Rev 5: 177-269

2. Yamagata K, Oda N, Kaisaki PJ et al. (1996) Mutations in the hepatocyte nuclear factor-1 $\alpha$ gene in maturity-onset diabetes of the young (MODY3). Nature 384: 455-458
3. Yamagata K, Furuta H, Oda N et al. (1996) Mutations in the hepatocyte nuclear factor- $4 \alpha$ gene in maturity-onset diabetes of the young (MODY1). Nature 384: 458-460

4. Vionnet N, Stoffel M, Takeda J et al. (1992) Nonsense mutation in the glucokinase gene causes early-onset non-insulin-dependent diabetes mellitus. Nature 356: 721-722

5. Stoffel M, Duncan SA (1997) The maturity-onset diabetes of the young (MODY1) transcription factor $\mathrm{HNF} 4 \alpha$ regulates expression of genes required for glucose transport and metabolism. Proc Natl Acad Sci USA 94: 13209-13214

6. Horikawa Y, Iwasaki N, Hara M et al. (1997) Mutation in hepatocyte nuclear factor- $1 \beta$ gene (TCF2) associated with MODY. Nat Genet 17: 384-385

7. Van den Ouweland JMW, Lemkes HH, Ruitenbeek W et al. (1992) Mutation in mitochondrial tRNA ${ }^{(\text {Leu)(UUR) }}$ gene in a large pedigree with maternally transmitted type II diabetes mellitus and deafness. Nat Genet 1: 368-371

8. Horikawa Y (2000) Genetic variation in the gene encoding calpain-10 is associated with type 2 diabetes mellitus. Nat Genet 26: 502

9. Fajas L, Auboeuf D, Raspe E et al. (1997) The organization, promoter analysis, and expression of the human PPAR- $\gamma$ gene. J Biol Chem 272: 18779-18789

10. Wu ZD, Xie YH, Bucher NLR, Farmer SR (1995) Conditional ectopic expression of c/ebp-beta in nih-3t3 cells induces PPAR- $\gamma$ and stimulates adipogenesis. Genes Dev 9: 2350-2363

11. Barroso I, Gurnell M, Crowley VE et al. (1999) Dominant negative mutations in human PPAR $\gamma$ associated with severe insulin resistance, diabetes mellitus and hypertension. Nature 402: 880-883

12. Auwerx J (1999) PPAR $\gamma$, the ultimate thrifty gene. Diabetologia 42: 1033-1049

13. Yen CJ, Beamer BA, Negri C et al. (1997) Molecular scanning of the human peroxisome proliferator activated receptor gamma (hPPAR $\gamma)$ gene in diabetic Caucasians: identification of a Pro12Ala PPAR $\gamma 2$ missense mutation. Biochem Biophys Res Commun 241: 270-274

14. Ek J, Urhammer SA, Sorensen TI, Andersen T, Auwerx J, Pedersen O (1999) Homozygosity of the Pro12Ala variant of the peroxisome proliferation-activated receptor- $\gamma 2$ (PPAR- $\gamma 2$ ): divergent modulating effects on body mass index in obese and lean Caucasian men. Diabetologia 42: 892-895

15. Deeb SS, Fajas L, Nemoto M et al. (1998) A Pro12Ala substitution in PPAR $\gamma 2$ associated with decreased receptor activity, lower body mass index and improved insulin sensitivity. Nat Genet 20: 284-287

16. Beamer BA, Yen CJ, Andersen RE et al. (1998) Association of the Pro12Ala variant in the peroxisome proliferator-activated receptor- $\gamma 2$ gene with obesity in two Caucasian populations. Diabetes 47: 1806-1808

17. Altshuler D, Hirschhorn JN, Klannemark M et al. (2000) The common PPAR $\gamma$ Pro12Ala polymorphism is associated with decreased risk of type 2 diabetes. Nat Genet 26: 76-80

18. Skarfors ET, Selinus KI, Lithell HO (1991) Risk factors for developing non-insulin dependent diabetes: a 10 year follow up of men in Uppsala. BMJ 303: 755-760

19. Mckeigue PM, Lithell HO, Leon DA (1998) Glucose-tolerance and resistance to insulin-stimulated glucose-uptake in men aged 70 years in relation to size at birth. Diabetologia 41: $1133-1138$

20. Clausen JO, Borch-Johnsen K, Ibsen H et al. (1996) Insulin sensitivity index, acute insulin response, and glucose effectiveness in a population-based sample of 380 young healthy 
Caucasians. Analysis of the impact of gender, body fat, physical fitness, and life-style factors. J Clin Invest 98: 1195-1209

21. Alberti KG, Zimmet PZ (1998) Definition, diagnosis and classification of diabetes mellitus and its complications. Part 1: diagnosis and classification of diabetes mellitus provisional report of a WHO consultation. Diabet Med 15: 539-553

22. Urhammer SA, Fridberg M, Hansen Tet al. (1997) A prevalent amino acid polymorphism at codon 98 in the hepatocyte nuclear factor- $1 \alpha$ gene is associated with reduced serum $\mathrm{C}$ - peptide and insulin responses to an oral glucose challenge. Diabetes 46: 912-916

23. Bergman RN, Prager R, Volund A, Olefsky JM (1987) Equivalence of the insulin sensitivity index in man derived by the minimal model method and the euglycemic glucose clamp. J Clin Invest 79: 790-800

24. Koch M, Rett K, Maerker E et al. (1999) The PPAR $\gamma 2$ amino acid polymorphism Pro12Ala is prevalent in offspring of Type II diabetic patients and is associated to increased insulin sensitivity in a subgroup of obese subjects. Diabetologia 42: 758-762

25. Jacob S, Stumvoll M, Becker R (2000) The PPAR $\gamma 2$ polymorphism Pro12Ala is associated with better insulin sensitivity in the offspring of type 2 diabetic patients. Horm Metab Res 32: 413-416

26. Vaag A, Alford F, Henriksen FL, Christopher M, BeckNielsen H (1995) Multiple defects of both hepatic and peripheral intracellular glucose processing contribute to the hyperglycaemia of NIDDM. Diabetologia 38: 326-336
27. Mancini FP, Vaccaro O, Sabatino L et al. (1999) Pro12Ala substitution in the peroxisome proliferator-activated receptor- $\gamma 2$ is not associated with type 2 diabetes. Diabetes 48: 1466-1468

28. Ringel J, Engeli S, Distler A, Sharma AM (1999) Pro12Ala missense mutation of the peroxisome proliferator activated receptor- $\gamma$ and diabetes mellitus. Biochem Biophys Res Commun 254: 450-453

29. Clement K, Hereberg S, Passinge B et al. (2000) The Pro115Gln and Pro12Ala PPAR $\gamma$ gene mutations in obesity and type 2 diabetes. Int J Obes 24: 391-393

30. Meirhaeghe A, Fajas L, Helbecque $\mathrm{N}$ et al. (2000) Impact of the Peroxisome Proliferator Activated Receptor- $\gamma 2$ Pro12Ala polymorphism on adiposity, lipids and non- insulin-dependent diabetes mellitus. Int J Obes 24: 195-199

31. Oh EY, Min KM, Chung JH et al. (2000) Significance of Pro(12)Ala mutation in peroxisome proliferator-activated receptor- $\gamma 2$ in Korean diabetic and obese subjects. J Clin Endocrinol Metab 85: 1801-1804

32. Hara K, Okada T, Tobe K et al. (2000) The Pro12Ala polymorphism in PPAR $\gamma 2$ may confer resistance to type 2 diabetes. Biochem Biophys Res Commun 271: 212-216

33. Mori Y, Kim-Motoyama H, Katakura Tet al. (1998) Effect of the Pro12Ala variant of the human peroxisome proliferator-activated receptor $\gamma 2$ gene on adiposity, fat distribution, and insulin sensitivity in Japanese men. Biochem Biophys Res Commun 251: 195-198

34. Luan J, Browne PO, Harding A-H et al. (2001) Evidence for gene-nutrient interaction at the PPAR $\gamma$ locus. Diabetes 50: 686-689 